\title{
Clinical responses observed with imatinib or sorafenib in melanoma patients expressing mutations in KIT
}

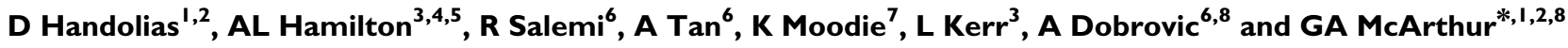 \\ 'Research Division, Peter MacCallum Cancer Centre, St Andrews Place, East Melbourne, Victoria 3002, Australia; ${ }^{2}$ Department of Medicine, St Vincent's \\ Hospital, The University of Melbourne, Melbourne, Victoria 3010, Australia; ${ }^{3}$ Department of Haematology, Royal Prince Alfred Hospital, 50 Missenden \\ Road, Camperdown, New South Wales 2050, Australia; ${ }^{4}$ Department of Medical Oncology, Sydney Cancer Centre, Royal Prince Alfred Hospital, 50 \\ Missenden Road, Camperdown, New South Wales 2050, Australia; ${ }^{5}$ Sydney Melanoma Unit, University of Sydney, Sydney, New South Wales 2006, \\ Australia; ${ }^{6}$ Molecular Developmental Research and Development Laboratory, Department of Pathology, Peter MacCallum Cancer Centre, St Andrews \\ Place, East Melbourne, Victoria 3002, Australia; ${ }^{7}$ Department of Diagnostic Imaging, Peter MacCallum Cancer Centre, St Andrews Place, East Melbourne, \\ Victoria 3002, Australia; ${ }^{8}$ Department of Pathology, The University of Melbourne, Parkville, Victoria 3010, Australia
}

BACKGROUND: Mutations in KIT are more frequent in specific melanoma subtypes, and response to KIT inhibition is likely to depend on the identified mutation.

METHODS: A total of 32 patients with metastatic acral or mucosal melanoma were screened for mutations in KIT exons I I, I3 and I7. RESULTS: KIT mutations were found in $38 \%$ of mucosal and in $6 \%$ of acral melanomas. Three patients were treated with imatinib and one with sorafenib. All four patients responded to treatment, but three have since progressed within the brain.

CONCLUSIONS: The observed clinical responses support further investigation of KIT inhibitors in metastatic melanoma, selected according to KIT mutation status.

British Journal of Cancer (2010) I 02, 1219-1223. doi:I0.1038/sj.bjc.6605635 www.bjcancer.com

Published online 6 April 2010

(c) 2010 Cancer Research UK

Keywords: melanoma; KIT; mutation; imatinib; sorafenib; brain

KIT has been identified as a of biological importance in melanoma, and mutations (and/or amplification) appear to be largely confined to acral and mucosal subtypes and those associated with chronic sun damage (Curtin et al, 2006; Beadling et al, 2008; Satzger et al, 2008). Clinical experience in patients with gastrointestinal stromal tumour (GIST) indicates that sensitivity and resistance patterns to the KIT kinase inhibitors can be predicted from the presence and location of specific KIT mutations (Heinrich et al, 2006). Patients with melanomas containing activating mutations in KIT have been reported to respond to imatinib therapy (Lutzky et al, 2008; Quintas-Cardama et al, 2008; Satzger et al, 2010); however, it remains uncertain whether mutations considered to be predictive of imatinib resistance can respond to second-generation KIT kinase inhibitors.

This report describes the frequency of KIT mutations in a prospectively selected group of Australian melanoma patients identified as 'at risk' of harbouring a KIT mutation based on clinical subtype. Four case reports illustrating significant clinical responses to kinase inhibitors highlight the therapeutic potential of KIT mutation screening in advanced melanoma. However, central nervous system (CNS) progression following systemic

\footnotetext{
*Correspondence: Professor GA McArthur;

E-mail: Grant.McArthur@petermac.org

Received 26 November 2009; revised 2 March 2010; accepted 4 March 2010; published online 6 April 2010
}

responses in three patients raises an important issue pertaining to treatment efficacy in the setting of brain metastases.

\section{MATERIALS AND METHODS}

\section{Patient population}

Patients from two melanoma centres in Australia (Peter MacCallum Cancer Centre, Melbourne and Royal Prince Alfred Hospital, Sydney) provided informed consent for KIT mutation screening if they had history of primary acral or mucosal melanoma between October 2006 and December 2008. Patients with metastatic melanoma requiring treatment were considered for a phase II clinical trial of imatinib (http://www.clinical trials.gov; NCT identifier: 00171912). Eligibility included the identification of an activating mutation in KIT predicted to be sensitive to imatinib, measurable disease as assessed by RECIST (Response Evaluation Criteria in Solid Tumours), normal organ function and an ECOG performance status between 0 and 2. Dosing commenced at 400 or $600 \mathrm{mg}$ daily with an option to escalate to 600 or $800 \mathrm{mg}$ depending on the response. Each participating institutional human ethics committee had previously reviewed and approved the study.

\section{Genotyping}

Genomic DNA obtained from 32 melanoma samples (23 metastases and 9 primary tumours) were tested for mutations in KIT 
(exons 11, 13 and 17) using high-resolution melting-screen analysis and confirmed by direct sequencing. Details of methods have been published previously (Handolias et al, 2010).

\section{RESULTS}

A total of 32 patient samples (16 mucosal and 16 acral) were analysed for mutations in KIT and 7 mutations were detected (Table 1). One acral melanoma contained an exon 17 (D820Y) mutation, representing a mutation frequency of $6 \%$ within this subtype. Six mucosal tumours (38\%) harboured a KIT mutation, and these spanned across all exons tested. Four patients with metastatic mucosal melanoma were treated with a kinase inhibitor, all of whom had heterozygous mutations confirmed by direct sequencing. Three consented to undergo a clinical trial of imatinib, and one patient with an exon 17 (D820Y) kinase domain mutation

Table I 'At-risk' population screening for KIT mutations

\begin{tabular}{|c|c|c|c|c|}
\hline Patient & $\begin{array}{l}\text { KIT } \\
\text { mutation }\end{array}$ & $\begin{array}{l}\text { Melanoma } \\
\text { subtype }\end{array}$ & Site & $\begin{array}{l}\text { Primaryl } \\
\text { metastasis }\end{array}$ \\
\hline 1 & WT & Acral & Fifth finger & Met \\
\hline 2 & WT & Acral & Thumb & Met \\
\hline 3 & D820Y exon 17 & Acral & First toe & Primary \\
\hline 4 & WT & Acral & First toe & Met \\
\hline 5 & WT & Acral & First toe & Met \\
\hline 6 & WT & Acral & First toe & Met \\
\hline 7 & WT & Acral & First toe & Met \\
\hline 8 & WT & Acral & First toe & Primary \\
\hline 9 & WT & Acral & First toenail & Met \\
\hline 10 & WT & Acral & Sole of foot & Met \\
\hline I | & WT & Acral & Sole of foot & Primary \\
\hline 12 & WT & Acral & Sole of foot & Met \\
\hline 13 & WT & Acral & Sole of foot & Met \\
\hline 14 & WT & Acral & Foot & Met \\
\hline 15 & WT & Acral & Heel & Primary \\
\hline 16 & WT & Acral & Heel & Met \\
\hline 17 & 7 codon dup exon 11 & Mucosal & Anal & Met \\
\hline 18 & D820Y exon 17 & Mucosal & Anal & Met \\
\hline 19 & V559A exon II & Mucosal & Anal & Met \\
\hline 20 & D816V exon 17 & Mucosal & Rectum & Met \\
\hline 21 & WT & Mucosal & Rectum & Met \\
\hline 22 & WT & Mucosal & Rectum & Primary \\
\hline 23 & WT & Mucosal & Nasal mucosa & Primary \\
\hline 24 & WT & Mucosal & Ethmoid sinus & Primary \\
\hline 25 & WT & Mucosal & Nasal septum & Met \\
\hline 26 & WT & Mucosal & Vagina & Met \\
\hline 27 & WT & Mucosal & Cervix & Primary \\
\hline 28 & K642E exon 13 & Mucosal & Vulva & Met \\
\hline 29 & WT & Mucosal & Vulva & Met \\
\hline 30 & WT & Mucosal & Vulva & Primary \\
\hline 31 & WT & Mucosal & Vulva & Met \\
\hline 32 & L576P exon II & Mucosal & Labia & Met \\
\hline
\end{tabular}

Abbreviations: $\mathrm{WT}=$ wild type; Met $=$ metastasis consented to treatment with sorafenib (off label use), because of predicted resistance to imatinib. All four patients had radiological and/or clinical response to therapy as described in the following case reports and as summarised in Table 2.

\section{Case report (1)}

A 65-year-old woman with a history of anal melanoma and resected splenic and cerebral metastases, developed a new pulmonary lesion 3 years later. A 21 base-pair duplication in exon 11 of KIT was identified in the splenic metastasis. On the basis of predicted sensitivity, she was commenced on a $600 \mathrm{mg}$ daily dose of imatinib and a $60 \%$ reduction in the pulmonary metastasis was observed at 12 weeks (Figure 1). After a further 3 months of treatment, she underwent whole brain irradiation for intracranial progression. After 1 year of continuing with imatinib, the patient had not developed any new systemic metastases but had advanced further within the brain and died of progressive CNS disease.

\section{Case report (2)}

A 48-year-old woman with a recurrent vulval melanoma containing a K642E mutation in exon 13 of KIT was treated with imatinib (400 mg daily dose) following loco-regional relapse 2 years after optimal surgical management and high-dose adjuvant radiotherapy. A significant reduction in the uptake on FDG PET was observed in the local recurrence, and there was complete resolution of soft tissue metastases at multiple sites after 3 weeks (Figure 2). The patient continued to respond to therapy with a $35 \%$ reduction in the sum of measured lesions on CT at 12 weeks (image not shown).

\section{Case report (3)}

A 38-year-old woman with a resected labial melanoma had an isolated clitoral recurrence after 3 years. Visceral metastases and a
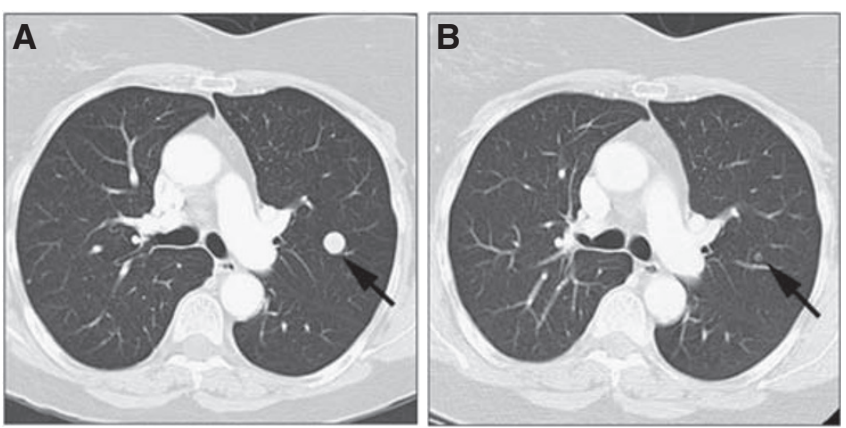

Figure I CT chest images of pulmonary metastasis arising from ana melanoma at baseline $(\mathbf{A})$ and then at 3 months $(\mathbf{B})$ showing reduction in the size of the lesion on imatinib (Case I).

Table 2 Summary of treatment response according to KIT mutation status

\begin{tabular}{|c|c|c|c|c|c|c|c|}
\hline Patient & Mutation & $\begin{array}{l}\text { KIT } \\
\text { inhibitor }\end{array}$ & $\%$ RECIST & $\begin{array}{c}\text { Best } \\
\text { response }\end{array}$ & $\begin{array}{c}\text { LDH } \times \text { ULN } \\
\text { baseline/best response }\end{array}$ & $\begin{array}{l}\text { PET } \\
\text { response }\end{array}$ & $\begin{array}{c}\text { CNS } \\
\text { relapse/progression }\end{array}$ \\
\hline । & 21 bp dup exon 11 & Imatinib & 60 & PR & I.1/0.8 & Yes & Yes \\
\hline 2 & K642E exon 13 & Imatinib & 35 & PR & $1.5 / 1.25$ & Yes & No \\
\hline 3 & L576P exon II & Imatinib & 42 & $\mathrm{PD}^{\mathrm{a}}$ & $12.5 / 1.2$ & NA & Yes \\
\hline 4 & D820Y exon 17 & Sorafenib & 27 & $\mathrm{SD}$ & $2.8 / 1.3$ & NA & Yes \\
\hline
\end{tabular}

Abbreviations: RECIST = response evaluation criteria in solid tumours; $\mathrm{NA}=$ not available, $\mathrm{PR}=$ partial response; $\mathrm{SD}=$ stable disease; $\mathrm{PD}=$ progressive disease; $\mathrm{LDH}=$ lactate

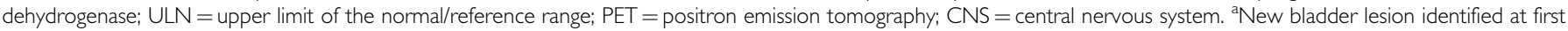
radiological assessment, despite dramatic clinical response and clear radiological response in pre-existing lesions. 
A

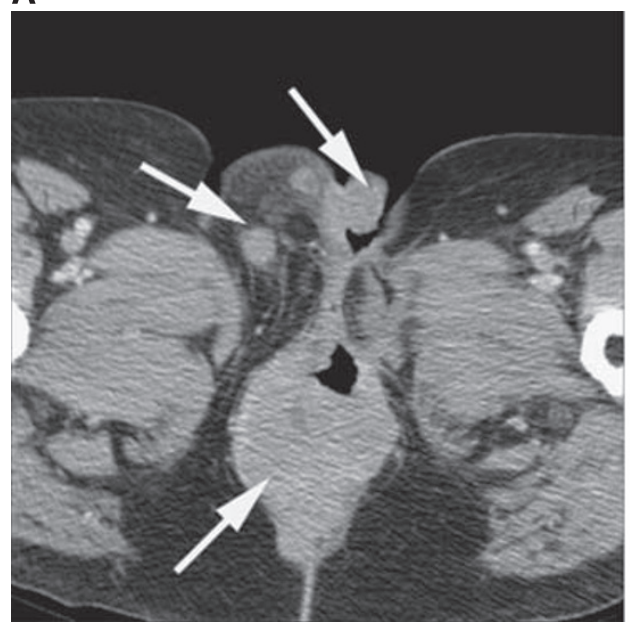

C

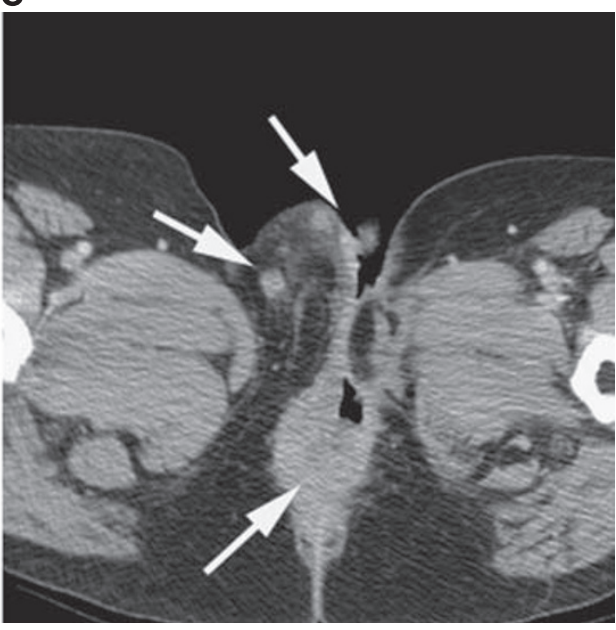

B

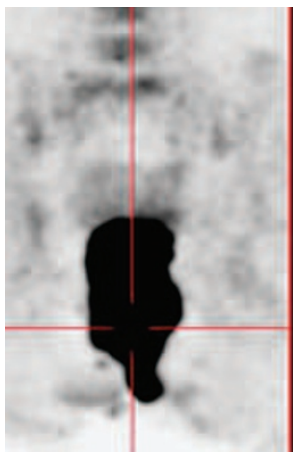

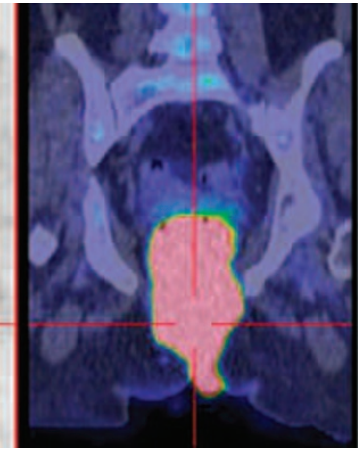

D

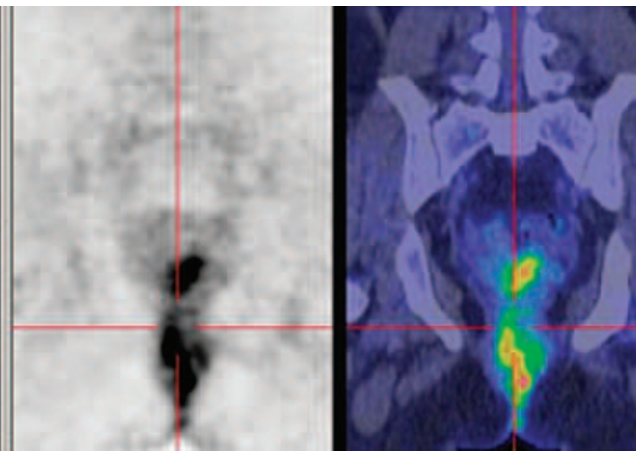

Figure 2 CT pelvis and FDG PET/CT images at baseline $(\mathbf{A}, \mathbf{B})$ and at I month $(\mathbf{C}, \mathbf{D})$ after treatment of a metastatic vulval melanoma with imatinib. Arrows indicate areas of response (Case 2).

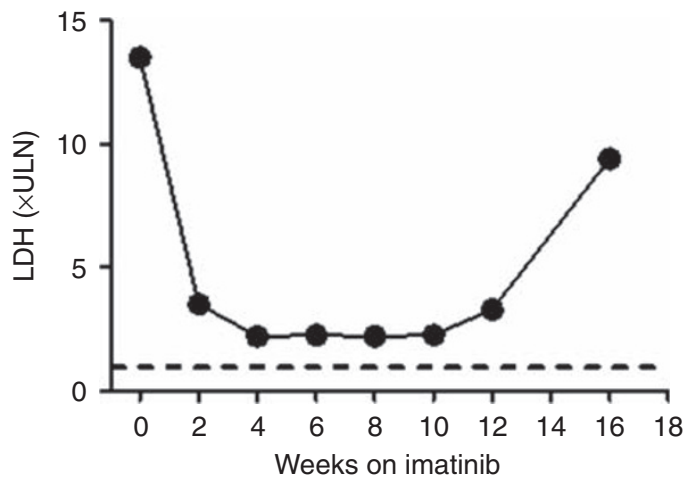

Figure 3 Marked LDH response within 2 weeks of commencing imatinib in a metastatic mucosal melanoma arising from the labia (Case 3). Dashed line indicates upper limit of the reference range.

soft tissue thigh mass were diagnosed 2 years later and unresponsive to standard chemotherapy. An L576P mutation in exon 11 of KIT was identified in the clitorectomy specimen and imatinib was commenced at a $400 \mathrm{mg}$ daily dose. The patient's symptoms improved dramatically within days and her LDH decreased from 2754 to $276 \mathrm{IUl}^{-1}$ (upper limit of reference range $=220 \mathrm{IU}^{-1}$ ) (Figure 3 ). A $42 \%$ reduction in the summed size of target lesions was seen on CT (image not shown). The patient then progressed at all sites despite an escalation in the dose of imatinib to $600 \mathrm{mg}$ and ceased treatment after 16 weeks, dying shortly thereafter with new brain metastases.

\section{Case report (4)}

A 62-year-old woman with anal melanoma and widespread pulmonary metastases complicated by impending respiratory failure, had a D820Y mutation in exon 17 of KIT in her primary tumour. She did not respond to chemotherapy and was ineligible for imatinib on clinical trial based on predicted resistance. Sorafenib was commenced ( $400 \mathrm{mg}$ b.i.d.), and within days, the patient was discharged from hospital without supplemental oxygen. Chest imaging at 4 weeks showed a $27 \%$ reduction in the sum of target lesions (Figure 4). Treatment was then interrupted because of gastrointestinal toxicity, and within 2 weeks, multiple brain metastases were diagnosed. Despite whole brain radiotherapy and re-introduction of sorafenib, the patient died from progressive CNS disease.

\section{DISCUSSION}

This case series can be seen as proof of two points of principle. First, clinical tumour characteristics have successfully been used to identify a subgroup of melanoma patients with a high prevalence of therapeutically relevant KIT mutations. Second, the genetic location of KIT mutation has successfully been used to guide selection of the KIT inhibitor in melanoma, echoing the broader 
A
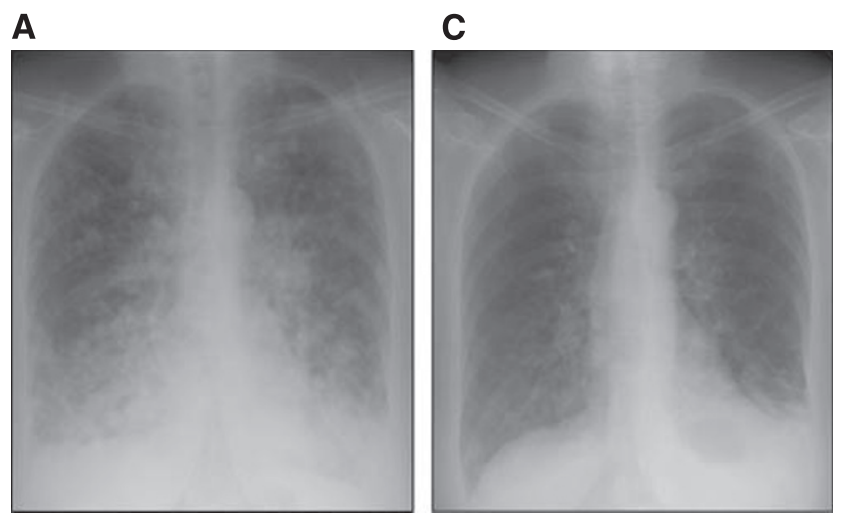

B

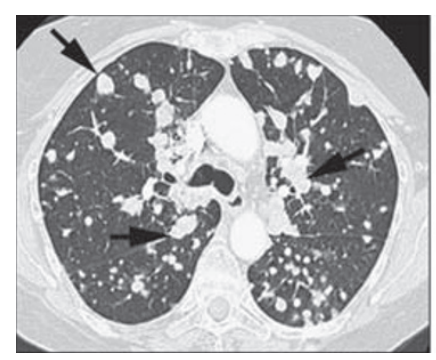

D

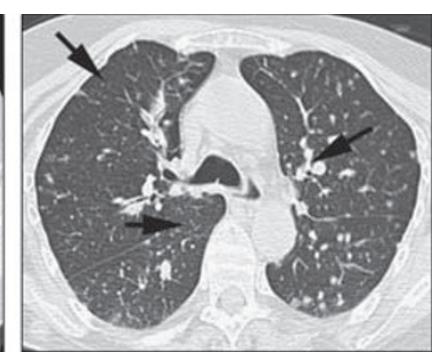

Figure 4 Chest $X$-ray and chest $C T$ images at baseline $(\mathbf{A}, \mathbf{B})$ and then at I month (C, D) after treatment of a metastatic anal melanoma with sorafenib demonstrates significant reduction in the number and size of pulmonary metastases. Arrows indicate major sites of response (Case 4).

experience of the use of KIT mutation subtype to select kinase inhibitor therapies in GIST (Heinrich et al, 2008).

Tyrosine kinase inhibitors demonstrate variable efficacy against KIT mutation variants in GIST. Mutations affecting the juxtamembrane region of the receptor result in its constitutive activation, and are particularly responsive to imatinib, whereas kinase domain mutations often confer resistance (Heinrich et al, 2003). The therapeutic responses to imatinib in this series mirror the clinical experience of other melanoma patients with similar sensitising KIT mutations (Hodi et al, 2008; Lutzky et al, 2008). The convincing clinical response observed in the patient with the L576P mutation in exon 11 (Case 3) is interesting to note in the context of in vitro data demonstrating reduced sensitivity to imatinib compared with other exon 11 mutations (Antonescu et al, 2007). It is possible that in this case, high imatinib concentrations were achievable within the tumour which resulted in the clinical effect. The non-sustainable response to therapy could also be explained by reduced drug levels over time as shown in pharmacokinetic studies of GIST patients wherein imatinib levels decrease with ongoing use because of increased drug clearance (Judson et al, 2005). It is likely that in these less-sensitive mutations, increased levels of imatinib or an alternative kinase

\section{REFERENCES}

Altintas A, Cil T, Kilinc I, Kaplan MA, Ayyildiz O (2007) Central nervous system blastic crisis in chronic myeloid leukemia on imatinib mesylate therapy: a case report. J Neurooncol 84: 103-105

Antonescu CR, Busam KJ, Francone TD, Wong GC, Guo T, Agaram NP, Besmer P, Jungbluth A, Gimbel M, Chen CT, Veach D, Clarkson BD, Paty PB, Weiser MR (2007) L576P KIT mutation in anal melanomas correlates with KIT protein expression and is sensitive to specific kinase inhibition. Int J Cancer 121: 257-264

Beadling C, Jacobson-Dunlop E, Hodi FS, Le C, Warrick A, Patterson J, Town A, Harlow A, Cruz III F, Azar S, Rubin BP, Muller S, West R,

inhibitor is required. Dasatinib has since been shown to have a selective inhibitory effect in this KIT mutation both in vitro and in the clinic in the setting of previous imatinib therapy (Woodman et al, 2009).

In GIST, mutations in the kinase domain of KIT are usually due to secondary point mutations (Kitamura and Hirotab, 2004) and can confer resistance to imatinib due to the altered conformation of the kinase which prevents drug interaction with the ATP binding pocket (Frost et al, 2002; Foster et al, 2004). The last case report in this series describes the treatment response seen in a patient with a D820Y mutation in exon 17 treated with sorafenib based on in vitro data predicting response (Guo et al, 2007). Sorafenib inhibits a number of kinases (Wilhelm et al, 2004) in addition to KIT, which cannot be excluded as contributing to the response to treatment seen in this patient.

The increased rates of CNS metastases in this series may be explained by the limited penetration of small molecule kinase inhibitors into the brain, as documented in other imatinibsensitive malignancies such as chronic myeloid leukaemia, Philadelphia chromosome-positive acute lymphocytic leukaemia and GIST in which relapse within the CNS has been reported (Takayama et al, 2002; Hughes et al, 2004; Altintas et al, 2007). This is likely to represent a significant clinical problem as the brain is a frequent site of relapse in melanoma. However, secondgeneration tyrosine kinase inhibitors such as dasatinib have shown some promise in Philadelphia chromosome-positive leukaemia patients with CNS involvement (Porkka et al, 2008). Furthermore, studies have looked at modulating the distribution of drugs such as imatinib by targeting P-glycoprotein and other drug protein transporters (Breedveld et al, 2005).

In conclusion, this report describes the clinical responses to KIT kinase inhibitors in melanoma patients harbouring diverse KIT mutations and supports the utility of selecting patients for therapy based on the identification of KIT mutations. This study did not test for KIT amplifications, which may also represent a melanoma subset sensitive to kinase-directed therapy. The demonstrated responses support the clinical testing of KIT inhibitors in the adjuvant setting in which potentially sensitive mutations in KIT have been identified, although the observation of frequent CNS relapse suggests that this may be a focus of ongoing research.

\section{ACKNOWLEDGEMENTS}

We thank Novartis for their financial support, Victoria Beshay for mutation screening, Boris Bastian, Glenn Lynch and Petranel Ferrao for discussion and Jill Magee, Chris Angel and Graham Mason for their pathology input. Thanks to Kathryn Kinross for assistance with images. This work was supported by grants from the NHMRC and a Sir Edward Dunlop Clinical Research Fellowship from the Cancer Council of Victoria (GA McArthur) and an Australian Postgraduate Award from the University of Melbourne (D Handolias).
Heinrich MC, Corless CL (2008) KIT gene mutations and copy number in melanoma subtypes. Clin Cancer Res 14: 6821-6828

Breedveld P, Pluim D, Cipriani G, Wielinga P, van Tellingen O, Schinkel $\mathrm{AH}$, Schellens JH (2005) The effect of Bcrp1 (Abcg2) on the in vivo pharmacokinetics and brain penetration of imatinib mesylate (Gleevec): implications for the use of breast cancer resistance protein and P-glycoprotein inhibitors to enable the brain penetration of imatinib in patients. Cancer Res 65: 2577-2582

Curtin JA, Busam K, Pinkel D, Bastian BC (2006) Somatic activation of KIT in distinct subtypes of melanoma. J Clin Oncol 24: 4340-4346 
Foster R, Griffith R, Ferrao P, Ashman L (2004) Molecular basis of the constitutive activity and STI571 resistance of Asp816Val mutant KIT receptor tyrosine kinase. J Mol Graph Model 23: 139-152

Frost MJ, Ferrao PT, Hughes TP, Ashman LK (2002) Juxtamembrane mutant V560GKit is more sensitive to imatinib (STI571) compared with wild-type c-kit whereas the kinase domain mutant D816VKit is resistant. Mol Cancer Ther 1: 1115-1124

Guo T, Agaram NP, Wong GC, Hom G, D’Adamo D, Maki RG, Schwartz GK, Veach D, Clarkson BD, Singer S, DeMatteo RP, Besmer P, Antonescu CR. (2007) Sorafenib inhibits the imatinib-resistant KITT670I gatekeeper mutation in gastrointestinal stromal tumor. Clin Cancer Res 13: 4874-4881

Handolias D, Salemi R, Murray W, Tan A, Liu W, Viros A, Dobrovic A, Kelly J, McArthur GA (2010) Mutations in KIT occur at low frequency in melanomas arising from anatomical sites associated with chronic and intermittent sun exposure. Pigment Cell Melanoma Res 23: 210-215

Heinrich MC, Corless CL, Demetri GD, Blanke CD, von Mehren M, Joensuu H, McGreevey LS, Chen CJ, Van den Abbeele AD, Druker BJ, Kiese B, Eisenberg B, Roberts PJ, Singer S, Fletcher CD, Silberman S, Dimitrijevic S, Fletcher JA (2003) Kinase mutations and imatinib response in patients with metastatic gastrointestinal stromal tumor. J Clin Oncol 21: $4342-4349$

Heinrich MC, Corless CL, Blanke CD, Demetri GD, Joensuu H, Roberts PJ, Eisenberg BL, von Mehren M, Fletcher CD, Sandau K, McDougall K, Ou WB, Chen CJ, Fletcher JA (2006) Molecular correlates of imatinib resistance in gastrointestinal stromal tumors. J Clin Oncol 24: 4764-4774

Heinrich MC, Maki RG, Corless CL, Antonescu CR, Harlow A, Griffith D, Town A, McKinley A, Ou WB, Fletcher JA, Fletcher CD, Huang X, Cohen DP, Baum CM, Demetri GD (2008) Primary and secondary kinase genotypes correlate with the biological and clinical activity of sunitinib in imatinib-resistant gastrointestinal stromal tumor. J Clin Oncol 26: $5352-5359$

Hodi FS, Friedlander P, Corless CL, Heinrich MC, Mac Rae S, Kruse A, Jagannathan J, Van den Abbeele AD, Velazquez EF, Demetri GD, Fisher DE (2008) Major response to imatinib mesylate in KIT-mutated melanoma. J Clin Oncol 26: 2046-2051

Hughes B, Yip D, Goldstein D, Waring P, Beshay V, Chong G (2004) Cerebral relapse of metastatic gastrointestinal stromal tumor during treatment with imatinib mesylate: case report. BMC Cancer 4: 74

Judson I, Ma P, Peng B, Verweij J, Racine A, di Paola ED, van Glabbeke M, Dimitrijevic S, Scurr M, Dumez H, van Oosterom A (2005) Imatinib pharmacokinetics in patients with gastrointestinal stromal tumour: a retrospective population pharmacokinetic study over time. EORTC Soft
Tissue and Bone Sarcoma Group. Cancer Chemother Pharmacol 55: $379-386$

Kitamura Y, Hirotab S (2004) Kit as a human oncogenic tyrosine kinase. Cell Mol Life Sci 61: 2924-2931

Lutzky J, Bauer J, Bastian BC (2008) Dose-dependent, complete response to imatinib of a metastatic mucosal melanoma with a K642E KIT mutation. Pigment Cell Melanoma Res 21: $492-493$

Porkka K, Koskenvesa P, Lundán T, Rimpiläinen J, Mustjoki S, Smykla R, Wild R, Luo R, Arnan M, Brethon B, Eccersley L, Hjorth-Hansen H, Höglund M, Klamova H, Knutsen H, Parikh S, Raffoux E, Gruber F, Brito-Babapulle F, Dombret H, Duarte RF, Elonen E, Paquette R, Zwaan CM, Lee FY (2008) Dasatinib crosses the blood-brain barrier and is an efficient therapy for central nervous system Philadelphia chromosomepositive leukemia. Blood 112: $1005-1012$

Quintas-Cardama A, Lazar AJ, Woodman SE, Kim K, Ross M, Hwu P (2008) Complete response of stage IV anal mucosal melanoma expressing KIT Val560Asp to the multikinase inhibitor sorafenib. Nat Clin Pract Oncol 5: $737-740$

Satzger I, Schaefer T, Kuettler U, Broecker V, Voelker B, Ostertag H, Kapp A, Gutzmer R (2008) Analysis of c-KIT expression and KIT gene mutation in human mucosal melanomas. Br J Cancer 99: 2065-2069

Satzger I, Kuttler U, Volker B, Schenck F, Kapp A, Gutzmer R (2010) Anal mucosal melanoma with KIT-activating mutation and response to imatinib therapy - case report and review of the literature. Dermatology 220: $77-81$

Takayama N, Sato N, O'Brien SG, Ikeda Y, Okamoto S (2002) Imatinib mesylate has limited activity against the central nervous system involvement of Philadelphia chromosome-positive acute lymphoblastic leukaemia due to poor penetration into cerebrospinal fluid. $\mathrm{Br} J$ Haematol 119: $106-108$

Wilhelm SM, Carter C, Tang L, Wilkie D, McNabola A, Rong H, Chen C, Zhang X, Vincent P, McHugh M, Cao Y, Shujath J, Gawlak S, Eveleigh D, Rowley B, Liu L, Adnane L, Lynch M, Auclair D, Taylor I, Gedrich R, Voznesensky A, Riedl B, Post LE, Bollag G, Trail PA (2004) BAY 43-9006 exhibits broad spectrum oral antitumor activity and targets the RAF/ MEK/ERK pathway and receptor tyrosine kinases involved in tumor progression and angiogenesis. Cancer Res 64: 7099-7109

Woodman SE, Trent JC, Stemke-Hale K, Lazar AJ, Pricl S, Pavan GM, Fermeglia M, Gopal YN, Yang D, Podoloff DA, Ivan D, Kim KB, Papadopoulos N, Hwu P, Mills GB, Davies MA (2009) Activity of dasatinib against L576P KIT mutant melanoma: molecular, cellular, and clinical correlates. Mol Cancer Ther 8: 2079-2085 